\title{
A Target Design of a Mobile App Providing Supportive Service for Flipped Classroom
}

\author{
Huan Cheng-lin ${ }^{1}$ \\ Chen Jian-wei ${ }^{2}$ \\ ${ }^{1}$ College of computer science, Yangtze University, No.1 Nanhuan Road, Jingzhou, China \\ ${ }^{2}$ Yangtze University College of Technology \& Engineering, No.85 Xueyuan Road, Jingzhou, China
}

\author{
Doi:10.5901/jesr.2016.v6n1p27
}

\section{Abstract}

With the continuous development of E-Learning, blended Learning which integrates online Learning and face- to- face Learning has gradually become a trend of Learning. Flipped classroom is an innovative teaching mode of blended learning. Flipped classroom caused the attention of many scholars and front-line teachers at home and abroad, but its most studies focused on the flipped teaching model and the application on subject, about research of flipped teaching supportive service is less. To some extent, the lack of network support services increases the difficulty to implement flipped classroom and limits its advantages. Therefore, the study about supportive service system of flipped classroom is necessary. This paper focused on the practice of flipped classroom in the educational reform. on the basis of connectivism learning theory and the analysis of the pattern of flipped classroom home and abroad, this article discussed the design study of structure, model and function module block of the mobile learning APP which supports the flipped classroom . So as to prepare for the development of mobile APP and seek for new idea and support for the effective practice of flipped classroom.

Keywords: flipped classroom, mobile learning, APP, connectivism

\section{Introduction}

With the continuous development of information technology and the deepening of teaching reform, flipped classroom has become a hot topic in education. It broke the traditional teaching mode, and has injected new vitality for the development of teaching reform . Compared with traditional teaching, flipped classroom is not only the change of the simple structure, but a profound innovation based on the respect to people and to cognition law. Information environment is not a must to the reform, but it offers abundant teaching resources and all-round support for interaction so as to fully mobilize different factors in teaching. With the popularity of personal computer and mobile terminal device, students generally changed from digital immigrants into digital natives. For today's students, mobile application are frequently used in daily life but still a new attempt in study. That's why it is on one hand familiar to students and fresh on the other hand. It can not only satisfy the teaching need but also give full play to students' initiatives. A mobile learning application , with perfect function and good users' experience will certainly act as a firm support for the effective practice of flipped classroom .

APP, short for application, is another name for third -party application. And most of the APPs are designed for phones with the popularity of Smartphone. Various educational APPs with novel design mushroomed in recent years .Many famous APP electronic stores such as iTunes APP store designed by the Apple company and Google Market designed for android users provide various learning APPs. However these applications are basically meet the general instructional need, thus often used for informal study. This study aimed at a target design of a mobile APP providing supportive service for flipped classroom. Thus, the advantage of this new teaching method can get full play and the teaching efficiency can be enhanced.

\section{Teaching Mode in Flipped Classroom}

\subsection{Definition of flipped classroom}

Flipped Classroom is a new type of teaching mode. Before class, students' independent study by watching instructional video at home instead of the teacher's lectures. In the classroom, students focus on finish the exercise and communication with peers and teachers. It upside down the traditional teaching arrangement- "the teacher teach in 
class, finish the homework after class". Two chemistry teachers, Jonathan Bergmann and Aaron Sam in Woodland Park High school in America firstly originated the flipped classroom theory. In 2007, they became courseware and Interpretation to teaching video by recording screen software, and uploaded to the internet for those students who cannot be in class to study[1]. As the two teachers' innovative teaching practice, flipped classroom became a new teaching mode, and were focused by the teachers over the world.

\subsection{Characteristic of flipped classroom}

The traditional teaching process usually includes knowledge teaching and internalization in two stages. Knowledge teaching is done by teachers in the classroom, and knowledge internalization is done through practice operation, do homework after class. This form has been reversed in flipped classroom. Accordingly, links and elements of teaching have been changed.

(1) Overcome the obstacle of time and space in teaching and learning: Teaching and learning behavior are conducted in a specific time and space when traditional teaching method is adopted. It is a great limitation in learning. While flipped classroom pattern makes an extension in teaching into extra-curriculum. Teachers release learning materials before class and keep the track of student's progress. Learners can begin their learning activities such as watching video, doing test, communication and so on.

(2) Role - reassignment between teachers and students: In the traditional form, teachers act as the one instructing students in knowledge and students the one accepting it passively. While in this mode, teachers are designers, developers and providers of learning materials in the pre-class stage. In the while - class stage, they are guides and helpers. And students are active knowledge seekers and constructors.

(3) Rearrangement in teaching structure: At present, there are three main teaching structures: the first one focus on teachers, the second one focus on students, and the third type characterized by the "guidance - focus "pattern. According to flipped classroom' thought, teachers and students take different role, and different activities are organized. So the teaching pattern belongs to no single structure but a reorganized of them.

(4) Digital learning resources and environment are guarantee of effective implementation of flipped classroom: Elearning environment is essential to such learning activities as releasing learning resources academic communication and cooperation, achievement presentation, evaluation and so on. With the knowledge instruction in face -to face form replaced, an elaborate design for the video as well as other learning materials that teachers provide and a proper presentation is necessary so that students can feel in a way that they are face to face with their teachers.

\subsection{The general learning process in the flipped classroom mode.}

Robert Talbert, a mathematics and computer science major in Franklin Institute in America, conducted a wide practice of flipped classroom to many courses such as linear algebra and how to solve problems using computer tools software. Over years' experience, he gave a summary of structure model of flipped classroom. [2] (As show in Fig.1)

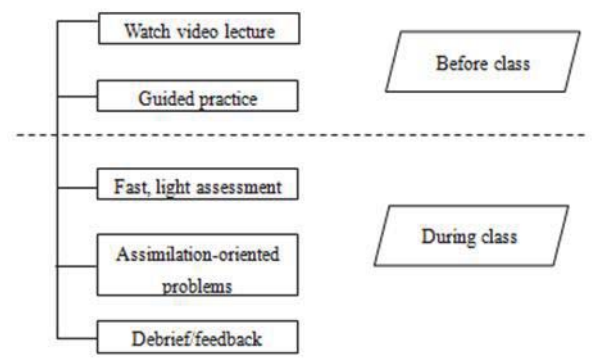

Figure 1. Flip the class structure ${ }^{1}$

${ }^{1}$ From Robert Talbert. Inverting the Linear Algebra Classroom[EB/OL]. <https://prezi.com/dzOrbkpy6tam/inverting-the-linear-algebraclassrooms 
This model gives a description of the main sections in flipped classroom, including watching video and doing correspondent exercise before class, finishing test, solving problems found in the test and give feedback.

Flipped classroom structure, incorporating three stages of pre-class self - study, while class internalization and post-class promotion, is designed by using the practice in Woodland Park High School and Clinton dale High School in Colorado America as well as the study conducted by Robert Talbert for reference. And it also incorporates the characteristic of digital medial a technology course as well as study in university. (As show in Fig.2)

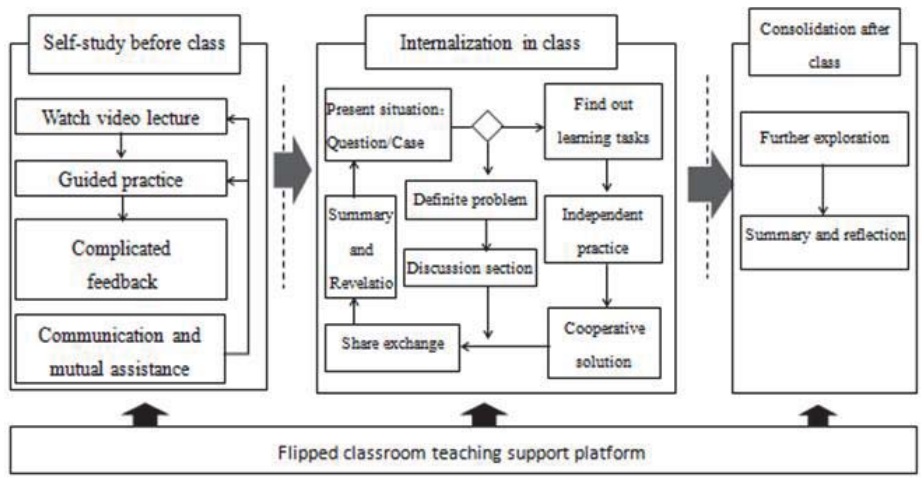

Figure 2. General process of flip classroom teaching implementation

Flipped classroom makes a reconstruction in teaching structure, a breakthrough in time and space(teaching is no longer limited to stipulated time and classroom, and students can accept education like traditional classroom teaching after class), and reshape the roles of teachers and students. And digital learning resources and environment are required for those changes. With the rapid development of wireless communication technology and the popularity of mobile terminal, mobile learning emerged as a way combines convenience and novelty. All the process from releasing learning materials, discussion, cooperation, presentation to evaluation in this pattern is based on mobile application. On condition that it is availability of internet facilities and each student has intelligent terminal, such as smart phone or IPad. These are all meet in my school.

Before the class, teachers release learning materials such as related videos, correspondent task by management terminal. Students begin their learning activities ------watching video, reading other materials, doing and handing in their online exercise -----through a certain APP installed in their mobile client. And if they meet with difficulties, a special part is designed in the APP for them to discuss with others .And teachers collect the difficulties arising.

During the class, teachers give students their task through the online platform ---APP. Students can search information or cooperation with others by it. They can present their study achievement or research conclusion on it when tasks are finished. Teachers give evaluations of students' performance and study outcome and issue learning materials for further study according to the progress students have made in class. All of these are achieved by APP.

After the class, students carry on a further study and research according to the supplementary materials and share with others their own learning experience as well as reflection in the personal zone in the app.

The development of this kind of client service system is not only practical but also necessary.

\section{The Mobile Learning APP Designed for Flipped Classroom}

\subsection{The design of the system architecture}

The B/S(Browser/Server) operating model is adopted in this kind of APP (as show in Fig.3). Teachers release, respond to and deal with information through the server which comprising web server, streaming server and database server. Students learn and communicate through the APP. 




Figure 3. Mobile learning APP system architecture

\subsection{The model of the learning APP}

In today's digital era, knowledge is dynamic and changes all the time. The connectivism theory gives a description of the learning process in the internet era, providing theoretical support for solving learning problems in this age. According to the theory that George Siemens put forward in the article: connectivism: A Learning Theory for the Digital Age. [3]Learning is no longer an internal individualistic activity but a process of connecting special nodes or information sources.

The modern knowledge is characterized by its ability to be connected, reorganized and recreated. [4] Based on connectivism learning theory and focused on knowledge, the mobile learning APP consists of three sub-modules: the connection part, the reorganization part and the recreation part. Learning content, situation, community and supporting tools are sub-elements of the above three parts. Those elements help and influence each other to support the mobile learning. ${ }^{[5]}$ (As shown in Fig.4)

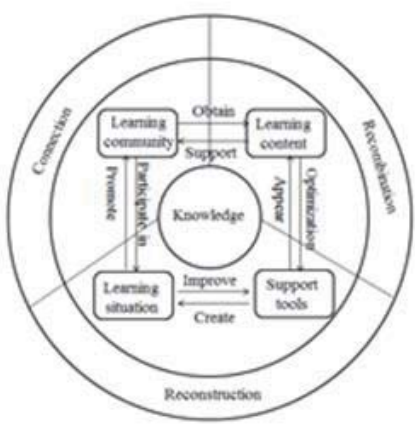

Figure 4. Elements of APP learning structure model

(1) The sub-module of connection: It makes sure that the learners keep in contact with the outside world any time and space, so as to keep the flow of knowledge available. In the flipped classroom supported by mobile APP, the connection of study in and out of class and the connection between teachers and students when they are not together are achieved by the using of wireless network and mobile equipment. The study community shares abundant information resources by wireless network, conducts learning communication, shares the fruit of study and establishes the knowledge links by such social platform as forums ,micro-blog and chat room.

(2) The sub-module of reorganization: The sub-module of reorganization is also called the sub-module of resources . In this part, knowledge, separated in different nodes in network, are reorganized and rearranged according to different learning need. And finally are presented to learners in a aggregated form of webpage or video. In this teaching pattern, all the mobile learning resources are reorganized based on the teaching structure: self-study before class, further study in class and promotion after class. The main resources 
include: micro visualized; learning materials, targeted exercise, and open-ended research materials and so on.

(3) The sub-module of recreation: It helps learners to establish their own knowledge system based on their prior one. This module includes two elements of learning situation and supporting tools. With the help of the convenience and flexibility of mobile device, classroom could be easier to be extended to the intuitive learning situation, which is of benefit to the meaning construction of knowledge. The supportive tools, as an extension of human body, help to achieve intelligent and diversified learning approach. The supportive tools in this patter mainly include the tools for information search, for communication and cooperation, for cognition and tools for location.

\subsection{The design of the functional module in the APP}

Under the guidance of connectivism, the APP includes three modules: the resources part, the connection part and the recreation part. The resources part is the basic and the target of learning behavior, the connection part is the guarantee and the road. These three parts are closely related and complementary to each other . The function module is designed according to the teaching process, and is shown in the following flowchart. [6] (As shown in Fig.5) The main structure is led by course catalog, and the node of the next level is a complete learning unit including four parts of information announcement, self-study before class, internalization in class and further development after class.

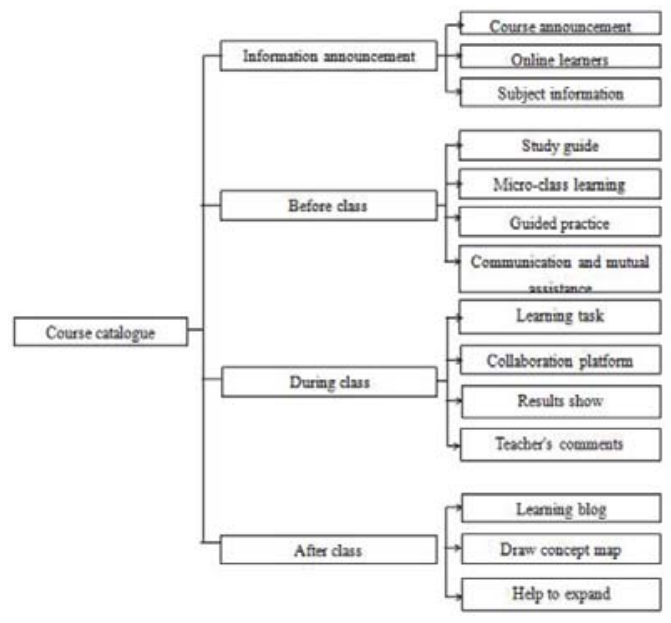

Figure 5. The function module of the mobile APP

\section{Conclusion}

Flipped classroom, as a new teaching pattern which flips the traditional teaching structure of instruction in class and internalization after class, can not be effectively implemented without the support of digital resources and environment.

Mobile learning, as a product of internet and mobile terminal, wins its popularity in contemporary students due to its convenience, personalization and entertainment features. And it must be an essential choice among the future learning methods. Based on the connectivism learning theory, this study follows the general process of flipped classroom and conducts design study in terms of structure, model and functional modules for the APP that supports the teaching pattern. It makes a demonstration on the feasibility of the development of APP.

\section{References}

The flipped classroom [EB/OL.2012-03-16. http://digitalsandbox.weebly.com/flipped-infographic.html.

Robert Talbert. Inverting the Linear Algebra Classroom[EB/OL]. http://prezi.com/dzOrbkpy6tam/inverting-the-linear -algebra-classroom 
George Siemens. Connectivism: A Learning Theory for the Digital Age [J]. Instructional technology \&distance learning, 2005,2(1):3-10. ZHANG Le-le,HUANG Ru-ming. A Critical Analysis of Environment Designing for Mobile Learning: a Reviewing of the Connectivism Theory, Morden educational technology,2013, 2(23):115-119

Jin Bu, Wang Xiao-gen, Wang Shu-yao, Hu Cong-quan. Content module framework design of mobile learning APP to support to flip classroom, software guide, 2014,7(13),52-54 